\title{
ON THE CUSP OF RECOGNITION: APPROPRIATING CRITICAL THEORY TO PROMOTE DESISTANCE AMONGST YOUNG OFFENDERS
}

\section{AN INTRODUCTION TO RECOGNITION AND REDISTRIBUTION IN CRIMINOLOGY}

Within the last two decades, criminologists have increasingly turned their attention to why offenders desist from a life of crime, at what point in their lifecycle and with what motivation. Many argue that desistance is not only prompted by internal processes of [re]alignment with conventional others, but also promoted by external opportunities for social integration (Farrall, 2002; Healy, 2013; Liem and Richardson, 2014; LeBel et al, 2008; Maruna, 2001; Sampson and Laub, 2005). Others suggest that desistance is severely undermined by political and economic forces which exacerbate the widening gap between affluence and deprivation and between youth and adulthood, and which encourage a greater focus on controlling individual behaviour rather than alleviating structural barriers (Barry, 2013; Garland, 2001; McAra and McVie, 2010; Wacquant, 2012; Young, 2007). However, despite the fact that the rate and frequency of crime peaks in the late teens and drops off for the vast majority of offenders in the late twenties, a counterargument to Gottfredson and Hirschi's (1990) claim that the age-crime curve is inexplicable continues to elude much criminological theory.

This article appropriates critical theory, in particular the concepts of recognition and redistribution, to enable a more nuanced examination of the processes of offending and desistance, and how those processes are steered, encouraged or constrained by wider socioeconomic forces, not least in the transition to adulthood. The discussion draws in particular 
on the work of Hegel, Honneth and Fraser, all of whom explore why and how individuals within a society may struggle for recognition, both as members of that society and autonomous beings within it. However, although critical theory on recognition has so far neglected the potential need for recognition amongst young people per se, this article argues that such a theory could be applied within a criminological context to address the issues of why most offending behaviour tends to occur in the so-called transition to adulthood and why young people may bear the brunt of misrecognition and marginalisation by the wider society because of their age and socio-economic status. The liminal status ${ }^{1}$ of youth restricts many young people's opportunities for recognition and integration within the 'moral mainstream' (Liem \& Richardson, 2014: 693), and youth offending could be seen as a manifestation of a need for recognition amongst those who perceive themselves to be marginalised because of their age.

However, the criminal justice system can severely curtail young people's motivation for and access to a conventional lifestyle. Desistance from crime and integration in adulthood thus require the proactive engagement of a) significant others to offer a sense of reciprocity and purpose for individual young people in the transition to adulthood, and b) the state to ensure that sustainable opportunities are in place which can encourage recognition within the moral mainstream; hence the importance of combining the dual concepts of recognition and redistribution to the aetiology of offending and desistance. Whilst the discipline of criminology acknowledges the crucial role of youth in the aetiology of crime, the concept of recognition has only been drawn upon to date within criminology at the micro level of interpersonal and relational dynamics to illustrate offenders' needs for integration with

\footnotetext{
${ }^{1}$ Van Gennep (1960) identifies the liminal period of the rite of passage between childhood and adulthood as depicting 'a cultural realm that has few or none of the attributes of the past or coming state' (quoted in Turner, 1967: 94-5). Turner (1969: 125) also describes the liminal phase as when people '(1) fall in the interstices of social structure, (2) are on its margins, or (3) occupy its lowest rungs'.
} 
significant others (see, for example, Benjamin, 1988; Gadd, 2006; Weaver, 2015). However, at the macro level, criminologists have yet to fully explore the sociological and political potential of recognition - and indeed redistribution - in the state's responsibilities to its citizens and vice versa (although see Barry, 2013, 2006; Young, 2007). Such concepts could well support the contention that young people are a potentially misrecognised group in the transition to adulthood because of their liminal status and that youth crime could be seen as a manifestation of a potential struggle for recognition in the absence of constructive opportunities for integration within the moral and economic mainstream.

Recognition is here defined as the giving and receiving of acknowledgement, encouragement and affirmation amongst individuals and groups which in turn promotes self- and socialidentity and respect. The concept, as used here, has two strands. First, recognition can be seen as an investment in others through the provision of opportunities which enable young people, for example, to become contributing members of mainstream society and in so doing acknowledges at least some progress towards gaining actual or potential achievements ${ }^{2}$, whether individual or shared. The investment of love, as espoused by Honneth (1995), is also critical for children and young people, not least when the giving and receiving of love denotes a relationship of mutual recognition. In return for both love from significant others and opportunities from the state, young people may invest their confidence, skills and commitment to a law abiding lifestyle by supporting others, for example through generativity $^{3}$, sustained employment and parenthood. Secondly, recognition can be seen as a reward in that it encompasses love, respect and esteem and ascribes to individuals and groups 'positive status' (Anderson, 1995: viii). However, for the first strand of 'investment'

\footnotetext{
${ }^{2}$ The recognition of achievements can result from personal hard work or aptitude and offers respect, pride, trust, status and other, for example monetary, rewards.

${ }^{3}$ Generativity or generative activities relate to feelings or behaviours that result from believing that one's past failings can be used to discourage future generations from experiencing the same challenges; ex-drug users, for example, often want to support other young people to prevent them becoming addicted to drugs.
} 
opportunities outlined above to be realised, redistribution (of income, employment, rights, responsibilities and status) is a necessary precondition of recognition, as illustrated in Fraser's (2003: 32) call for parity of participation ${ }^{4}$. Indeed redistribution is part of that investment in young people which confers on them recognition within the moral mainstream.

Within the discipline of political philosophy, the concept of recognition is primarily used in the context of explaining the struggles of individuals or minority groups for the reward of integration or identity based on race, gender or sexuality (Fraser, 2003; Honneth, 2003), and to overt struggles for a politics of difference (Laitinen, 2003). Within the discipline of criminology, however, I would argue that recognition needs to combine investment (from the state), namely in opportunities associated with conventional or mainstream society such as employment, accommodation, income and education through which individuals can use their skills and experience to contribute to the common good, with reward for achievements bestowed on individuals/groups by those who such individuals/groups themselves recognise as commanding respect. Both investment and reward are implicit in a sense of reciprocity, where the input, output or status of both the recognised and the recogniser is, or is perceived to be, morally and/or practically beneficial to the common good, thereby encouraging mutual trust, respect and esteem.

This article firstly highlights some of the current debates and gaps within desistance theory before exploring recent critiques of the concepts of recognition and redistribution emanating from political/philosophical debates within critical theory. In illustrating the relevance of these debates to the study of desistance within criminology, the article draws on the findings

\footnotetext{
${ }^{4}$ Fraser (2003) argues that parity of participation requires two conditions, first that there is no instititutionalized deprivation, exploitation or disparities in income/wealth, and secondly, that there is no discrimination of certain categories of people because of difference. If either of these two conditions is not met, claims for recognition are justified, in order to achieve greater parity of participation.
} 
from an ESRC-funded (grant reference: Res-061-30-000156) empirical study of current and ex-offenders where issues of recognition are seen as impacting on their propensity or otherwise to desist from crime. These findings are subsumed under the headings of a) the search for recognition in childhood; b) misrecognition from the criminal justice system in youth; and c) gaining recognition through integration in early adulthood. The article concludes with a discussion of the potential influence of recognition and redistribution on criminal justice and wider social policy/practice in furthering the longer-term desistance of young offenders.

\section{THE LIMITATIONS OF CURRENT DESISTANCE LITERATURE}

Desistance is the process of giving up crime, whether socially engineered or individually instigated . From being seen in the 1990s as resulting almost by default from external factors such as employment or marriage (Sampson and Laub, 1993; Shover, 1996), the process of desistance in recent years has focused more on the efforts of the individual to either embrace or [re]align themselves with law-abiding behaviour, albeit within the confines of structural constraints (Burnett, 2004; LeBel et al, 2008; Maruna, 2001). Young offenders in particular are seen to grow out of crime (Rutherford, 1986), are deterred by the costs incurred of criminal justice system involvement (see Gadd and Farrell, 2004 for a résumé), or attempt over time to adopt pro-social attitudes or identities (Farrall, 2002; Giordano et al, 2002; Maruna, 2001). Liem and Richardson (2014) suggest that of Maruna's (2001) three facets of transformation narrative - a good core self, generative motivations and individual agency only that of individual agency is key to a successful desistance process. Other commentators suggest that, irrespective of individual agency, would-be desisters are inevitably influenced 
by the nature and quality of their social bonds, their access to employment, and the impact of 'turning points' on their lifestyle choices (Sampson and Laub, 1993, 2005; Shover, 1996).

However, the prevalence of external barriers to crime-free lives, and the inability of criminal justice systems per se to exert anything other than a reactive and reaffirming influence on wider social policy, are often obscured in theoretical accounts as much as in policy analyses (see, for example, Burnett, 2004; Maruna, 2001). The desistance literature remains primarily wedded to an individualisation discourse, partly because [non]offending behaviour is seen (not least by policymakers) to be a matter of individual choice, but also partly because such a discourse absolves politicians from any blame for or acknowledgement of underlying structural inequalities. Nugent and Barnes (2013: 22) argue that by focusing on individual young offenders in criminal justice policy, 'the questions that should be asked of society can remain unanswered' and that desistance research should not encourage us to become 'complacent in accepting that just helping young people to stop offending is good enough'.

It is argued here that the desistance process requires proactive engagement, not just from would-be desisters in finding opportunities to desist from crime, but also from policymakers and the wider society in ensuring these opportunities are available to all and not just to a few. And yet the desistance literature focuses primarily on what is possible within the sociopolitical confines of the status quo and within the limited interventions of the criminal justice system, leaving much of the work of desistance to would-be desisters (see Barry, 2013; Hart, 2014 for a critique). Individual traits such as decision-making, cognition, motivation, hope and resilience are increasingly seen as crucial factors in the process of desistance (Healy, 2010; LeBel et al, 2008; Maruna, 2001; Morizot and Le Blanc, 2007; Vaughan, 2007), and yet what is missing both from offenders' lives and from the desistance literature is the 
ingredient of 'exchange' or 'reciprocity' in interactions with others. It is therefore to the concepts of recognition and redistribution that I now turn: concepts which form two distinct yet integral parameters of social justice.

\section{THE CONCEPTS OF RECOGNITION AND REDISTRIBUTION}

The concept of recognition as espoused by social philosophers relates primarily to the need for mutual acknowledgement and the resultant struggles for identity and diversity within a given society if that acknowledgement is denied. Hegel's early $19^{\text {th }}$ century writings (Harris \& Knox, 1979; Rauch, 1983) were a critique of previous natural law treatments which, according to Honneth:

conceive of the purportedly "natural" form of human behaviour exclusively as the isolated acts of solitary individuals, to which forms of community-formation must then be added as a further thought, as if externally (Honneth, 1995: 12).

Hegel argued that theories of society should be more concerned with 'the framework of ethical bonds' than with 'the acts of isolated subjects' (Honneth, 1995: 14). Ethical bonds and ethical life refer here to the norms and values of a given community where intersubjective coexistence is the priority, as exemplified by the love and attention of significant others, which in turn can offer increased self-confidence, self-respect and self-esteem (Honneth, 1995). If an individual is in conflict with his/her community, this tends to be because of a lack of recognition of that individual's particular self and social identity within a collective social life (self-realisation through mutual recognition) and not because of self-preservation. 
As Anderson (1995: xviii) reiterated in his translator's introduction to Honneth's (1995) thesis:

The point of reference for esteeming each individual is the evaluative framework accepted by the entire community and not just one subculture... the central point is that, in pluralistic and mobile societies, it is difficult to maintain self-esteem in the face of systematic denigration from outside one's subculture.

Hegel 'traces the emergence of crime to conditions of incomplete recognition' (Honneth, 1995: 20), and although Honneth builds on Hegel's theoretical development of the intersubjective struggle for recognition of one's identity, he fails, however, to take up the issue of crime as a potential struggle for recognition, focusing instead on the need by individuals for reciprocal bonds of love, respect and esteem in discrete social relationships. To Honneth, only by acknowledging and being acknowledged by significant others can one gain self-realisation. Honneth (2007: 71) thus sees recognition as the reciprocal expectation of subjects 'that they be given recognition as moral persons and for their social achievements', a respect for one's own dignity and integrity without which human identity is lost. Honneth concludes that without recognition, feelings of disrespect (shame, anger or indignation) and injustice will result; in other words, without recognition, social justice cannot be sustained.

Fraser, however, argues that Honneth's definition of recognition is too narrow and individually-focused, and that social justice requires recognition and redistribution: "virtually every struggle against injustice, when properly understood, implies demands for both redistribution and recognition' (Fraser, 1995: 70). She advocates a critical theory of 
recognition which incorporates the cultural politics of difference with the social politics of equality. She argues that struggles for recognition are invariably aligned with material inequality, and that a critical theory of recognition 'identifies and defends only those versions of the cultural politics of difference that can be coherently combined with the social politics of equality' (ibid, 69). Maldistribution (class subordination) and misrecognition (status subordination) are injustices in their own right but require to be addressed in tandem to achieve Fraser's (2003) parity of participation.

Fraser (1995) identifies two types of injustice: socioeconomic injustice, as exemplified by exploitation, economic marginalisation and deprivation, and cultural injustice, as exemplified by cultural domination, non-recognition and disrespect/misrecognition. Fraser argues that where a group lies nearer the centre of the continuum between the two extremes of socioeconomic injustice and cultural injustice, she refers to such groups as 'bivalent', giving the primary examples of race and gender:

Bivalent collectivities, in sum, may suffer both socioeconomic maldistribution and cultural misrecognition in forms where neither of these injustices is an indirect effect of the other, but where both are primary and co-original. In that case, neither redistribution remedies alone nor recognition remedies alone will suffice. Bivalent collectivities need both (Fraser, 1995: 78).

This article argues that young people are also a bivalent collectivity, being subject to both socioeconomic and cultural injustice because of their age and liminal status. Young people are often disadvantaged in the liminal phase between childhood and adulthood (Barry, 2006), can be marginalised and exploited in the labour market, and tend to bear the brunt of 
increasing criminalisation and stigmatisation resulting from criminal justice and wider social policy. However, neither Fraser nor Honneth (2011, pers. comm) extend their analyses to include age as a minority status, and the fact that young people can be disadvantaged or marginalised in terms of access to rights, respect and recognition. Laitinen (2003) comes closest amongst critical theorists in acknowledging the vulnerability of youth in recognition theory and the role of liminality in undermining the ability of recognition to transform potentiality into actuality. He suggests that potential personhood becomes actual only when it is recognized by others, and that 'recognition from others seems to play a significant role in the development processes where human persons learn to be agents of recognition themselves' (Laitinen, 2003: 6). Appropriating a theory of recognition and redistribution in criminological terms therefore needs to take age into account, not least the liminal phase of youth where age inequality and status deprivation can be particularly pronounced. The following section thus discusses the concepts of recognition and misrecognition from an empirical rather than theoretical perspective, through an exploration of the potential effects of misrecognition and maldistribution as experienced (but not necessarily made explicit) by young offenders themselves.

\section{APPLYING RECOGNITION THEORY TO A STUDY OF DESISTANCE}

In 2000, in-depth interviews were undertaken with 40 young people aged 18-33, with the aim of exploring their reasons for onset and desistance. The study focused on ex-clients of a Scotland-wide intensive probation programme for young adult offenders, notably those with $3+$ previous convictions who had been on intensive probation. Ten years later, in 2010, with funding from the ESRC, a follow up study of half of those offenders was undertaken (then aged 29-43) and was combined with a new sample of 20 younger offenders/ex-offenders 
(aged 21-33) who were recruited from the same sources and using the same criteria as the original sample, albeit 10 years later. The original sample had an average of 35 previous convictions and their offending histories had lasted on average 13 years to date with 15 saying at interview that they had stopped offending. The new sample had an average of 30 previous convictions and their offending histories had lasted on average 7 years to date with 14 saying they had stopped offending. Both samples were primarily involved in the typical street crimes commonly associated with disadvantaged and disaffected adolescents and young adults, namely, theft, assault and drug-related violence.

Although the word 'recognition' was not overtly used in discussions with young people in the sample, the interviews covered experiences of offending and desistance, and perceived identities, responsibilities and achievements. These interviews were semi-structured in that people were asked to expand on various aspects of their lives and experiences. Four individual respondents' stories are drawn on here to illustrate the possible transitions from offending to desistance and how the concept of recognition might impact on those transitions. Hollway and Jefferson (cited in Gadd and Farrell, 2004) argue that such cases should be selected on the basis that they are theoretically interesting. Certainly, the four respondents chosen here help illustrate, however inadvertently, the relevance of the concepts of recognition and redistribution to criminology. They comprise 3 women - Emma, aged 26, who was still offending at the time of interview; Anna, aged 31, who stopped 6 years previously and Carol, aged 39, who stopped 3 years previously - and one man, Vic, aged 33, who stopped a year previously. These case studies offer specific perspectives on offending, recovery, desistance and recognition, and are interspersed in this article, where appropriate, with additional illustrations from other respondents within the overall sample. 


\section{Liminality and the search for recognition in childhood}

Many of the respondents in this study spoke about loss in childhood, whether through bereavement or the withholding of love and attention by parents, and this loss was perceived by these respondents as a trigger to seeking alternative sources of reciprocal love and attention within the peer group. For example, Anna had no love from her parents as a child as she saw both parents as strict and uncaring. She suggested that her parents could have prevented her offending escalating if they had given her more love and respect:

If my mum and dad had been less possessive and let me do my own thing... If I'd more love. I mean, if my mum and dad showed me love instead of just being strict... if my mum had been a better mother to me (Anna).

The lack of love and attention in childhood and youth often creates a feeling of having 'nothing else to lose', and many of the sample suggested that they had little incentive or opportunity through which to gain recognition within the moral mainstream. For example, those with traumatic family upbringings, especially the young women, often suggested they sought alternative love and attention from older peers or relationships with older partners, most of whom were offending. They also compensated for the loss (of parental love, of a close relative/friend through death, of childhood innocence through sexual abuse) by seeking status and recognition with peers in the school environment, and those most vulnerable to isolation or marginalisation were those most likely, in the absence of alternative sources of recognition, to choose to offend as a means of giving and receiving attention or 'buying' friends, as exemplified by the following quotation. 
It was just to prove to the older people that I could do it just as well as them. [And] basically just to get attention, I think. I wanted all the loving and caring that I could get because my dad worked all the time and... I thought I was great. I could do this and I could do that. Like I could just walk into a shop and help myself to whatever and, as I say, it was just stupid things, it was just maybe a couple of crème eggs or a couple of bars of chocolate, and going out to your mates and going 'look what I've got, whey hey!'... it was like I was buying my friends by doing what I was doing (Carol).

Coupled with a lack of parental supervision which was often perceived as a lack of love and attention, many of these young people had no one to turn to for recognition and support except their peers. One woman also felt the need to 'buy her friends' and prove worthy of their friendship through offending:

I was bullied a lot and to get friends I done silly things to get attention, like went into shops and stole things.... I was looking for attention from my peers basically and I done the silliest things to get it, because I didn't really know how to interact with them otherwise (Rhona, aged 32).

One young man, whose childhood had been one of inconsistent parenting and geographical upheaval, also escaped a traumatic family environment by seeking attention from peers, whom he described as 'a surrogate family':

My mother was literally in the pub all the time and stuff. I could do what I wanted and I did what I wanted... I didn't have family at that point as far as I was concerned. I 
think that's probably what I was looking for, a surrogate family... I think I was trying to get [friends] to fill in the gaps in my life that were missing (Pete, aged 29).

Following domestic abuse throughout his childhood, Vic also sought comfort from peers, despite reflecting back that they were 'the wrong crowd'. He was proud of his reputation in youth as a prolific shoplifter, a source of recognition not only from his peers, but also the police: 'I know I'm good at it. A lot of people have told us. The police and that have told us'. And yet this source of recognition, pride and achievement came with a price, either of violence, addiction or imprisonment.

Anna and Emma sought recognition from older male drug users despite being introduced by them to heroin and crime, but any recognition gained from these relationships was short-lived because of their involvement in the criminal justice system:

I lost my family and my house, everything... See when I get out [of prison], I've not got my family, right. I've not got my bairns, so I think well fuck it, why should I even bother cos no cunt bothers about me, so why should I care? (Emma).

Emma epitomises the misrecognition and disempowerment facing disadvantaged young people and the almost futile nature of any struggle for desistance or integration because of the stigma of being involved in the criminal justice system, as illustrated below.

\section{Misrecognition from the criminal justice system in youth}


The vast majority of young offenders have aspirations for normality ${ }^{5}$ rather than criminality (Barry, 2006; Farrall, 2002; Shapland and Bottoms, 2011). Yet, despite their agency and resilience, such young people often do not feel a part of mainstream society and find integration difficult in terms of employment, income, support networks, not least because of their involvement in the criminal justice system. Many of the sample suggested that they had little incentive or opportunity to prove their desire and potential for change, as a result of their offending history. Vic's opportunities to gain recognition from legitimate sources in his early twenties had been constrained by the revolving door of imprisonment. When first interviewed in prison in 2000, Vic did not see the point in trying to stop offending, as there was no alternative source of income or status and no encouragement from the criminal justice system.

Every achievement I've had, it's just been flung away. Tried anything, it's just boof. It's like I restart every time I come in here [prison], I've got to get out and start something [new]... You keep coming back like in here and you never get a chance. It's just you do one thing, you go to jail, you do another, you go to jail, there's no other way round it (Vic)

Ten years later, despite keeping out of trouble for a year, he was still doubtful as to whether trying to stop offending was worthwhile: 'I'm not meant to have the good things in life, so what's the point of doing anything with my life, cos I can't go out and get a job cos of my criminal record from my past' (Vic). He was still harassed by the police and discriminated against by employers because of his criminal record. Despite Vic recognising the rule of law, few professionals correspondingly recognised him as having the potential to 'make good'. As

\footnotetext{
${ }^{5}$ Young offenders invariably talk of wanting to lead a 'normal' life, to be 'normal' or to experience 'normality' through giving up crime (Barry, 2006; Shapland and Bottoms, 2011).
} 
Canton (2012: 580) suggests: '[offenders] are defined in terms of their offending behaviour, as offenders, even though this is the very identity it is hoped they will repudiate'. It is little wonder, perhaps, that young people in the liminal phase of youth resort to crime as a means of counteracting such societal misrecognition. Those who are deprived and misrecognised face humiliation as well as a sense of being nothing (Young, 2007), and those without employment or income epitomise the lack of one crucial element of recognition, the sense of reciprocity between the state and its citizens. A recent study (Princes Trust/Macquarie, 2014) found that approximately 10 per cent of unemployed young people believe they have nothing to live for and this figure increases to more than 20 per cent amongst the long-term unemployed. Nearly three-quarters of unemployed young people also state that they have no one to turn to for support, and that the recognition gained from offending peers is an obvious alternative to loneliness, isolation and disaffection. If there is no recognition of one's potential or actual achievements, and no opportunities to remedy that situation, then resentment of the mainstream may result in underhand means of achieving goals (Merton, 1957) and consequent marginalisation and stigmatisation.

Those who had drug problems and children (whether or not within their care currently), had to contend not only with a punitive criminal justice system but also with a risk-averse Children and Families Social Work Department, which in Scotland has the right to remove children to residential or foster care in cases of potential parental neglect. Anna's first daughter from a volatile relationship with an older drug addict was taken into care because of Anna's heroin addiction, and she was fighting to get her back, having been told it could be 5 years before they would consider returning her daughter to her care depending on Anna's future behaviour: 
I'm trying to sort my head out and people aren't giving me the chance. You know, people just see me as a smackhead, down and out, junkie... I've lost my daughter, I've got nothing else to lose, so basically I've lost everything (Anna).

Not being given the chance was a common complaint by those trying to desist from crime. They felt they were making the effort to become law-abiding and yet faced constant misrecognition as offenders. For example, Anna was known in the area as an offender in 2000, and this prevented her from moving on in life:

I nearly had a job. I was supposed to be starting that next week in one of the pubs in [town] and the man wanted me to start but then they went and spoke to the [bosses] and [they] said: '[Anna?] No'. They wouldn't give me the job.... When you're treated like a scumbag, it makes you feel low and you think what's the point in changing? Everyone thinks that of me anyway, so what's the point? If you're treated like everyone else, you act like everyone else. What's the point? No one believes me. Why should I change if no one sees the changes? ... For years I was told by services, you'll never, you know, you'll never come off [heroin], you know. You'll never do that. I was told in prison, you're gonna be back here, in and out of prison for the rest of your life, you know, and things like that didn't help at all, because it just made me think [sigh].... You've got to want to change and positive feedback helps. If you want to change and you keep getting brought down, you're never gonna, cos you know... they don't believe me, so why should I believe myself? (Anna). 
The above quotation epitomises the impact of misrecognition on young people in transition the denigration of status, the negative labelling ${ }^{6}$ and the resultant despair - and as Taylor (1992: 36) notes:

[A] person or group of people can suffer real damage, real distortion, if the people or society around them mirror back to them a confining or demeaning or contemptible picture of themselves... [as a] reduced mode of being... so that even when some of the objective obstacles to their advancement fall away, they may be incapable of taking advantage of the new opportunities.

Whereas 'misrecognition' is the active degradation of an individual or group, a 'lack of recognition' is a more passive, inadvertent 'neglect' of people's need for a sense of social and community identity. This neglect is manifest in a sense of feeling unsupported and uncared for. For example, Emma, in prison at the time of the interview in 2010, was feeling particularly pessimistic about the future, not least with the failure to address her drug problem on leaving prison:

They send you out the door [of prison] and put you into a homeless hostel that's full of drugs and expect you to stay clean... It's hard when you're outside. It's the people. I've been used to this now for about 9 years, so everybody I see is on it [heroin], so it's really hard to break yourself away from it.... [Interviewer: What have you got to lose by reoffending?] Nothing. I've lost everything, so I've nothing to lose. I've got

\footnotetext{
${ }^{6}$ Whilst labelling theory suggests that such societal reactions will exacerbate offending behaviour, and whilst many of these respondents expressed frustration at the negative labelling they received, recognition theory implies that internalisation of the label of 'offender' can be overcome through a reciprocal exchange between would-be desister and would-be recogniser.
} 
everything to gain but I've not really. I don't have nothing to lose. My clothes, that's it. That's all I own, my clothes. It's sad. It's sad like, it is' (Emma).

Emma wanted to stop offending but as with many of her contemporaries, she could not see the point: 'You get absolutely pure sick of the life and you think, fuck it... I wish there was an alternative but there isn't'. Moloney et al (2009: 314) argue that offenders need to have that alternative - 'something or someone to care for and about... a reorientation to a life with a future and new possibilities... something to live for'. Whilst the self-determination and agency required to 'knife off' an embattled past (Maruna, 2001) is fully acknowledged, it could be argued that those external opportunities must come first - 'an affirmative alternative', as Moloney et al describe it (2009: 319). The lack of alternatives to an offending lifestyle and the often minimal professional support and encouragement given to the young people in this study to desist from crime is worrying and it is perhaps little wonder that young people may entrench themselves in a group of peers 'against a hostile majority' (Bromley, 1993: 33).

\section{Recognition through integration in early adulthood}

It is only when disadvantaged young people manage to extricate themselves from the structural void of the liminality of youth that the power differential reduces between themselves and 'adults' and a semblance of equality of status and opportunity becomes more attainable. It could be argued that recognition gained and given in the 'homestretch' of adulthood (for example, through achieving qualifications, finding meaningful employment and taking on responsibilities for oneself or others) is more sustainable, more reciprocal and has fewer negative repercussions than that gained in youth through illegal means. 
Recognition gained in adulthood is also a positive, durable and attractive alternative to offending behaviour (Barry, 2006). Only a minority of this sample had opportunities to look forward to in adulthood, but most nevertheless started the process of dismantling their previous lifestyles in anticipation of potential recognition in the future. When asked what had been the major achievements in their lives to date, the most common response, albeit mainly from the young women, was having children, coming off drugs, gaining qualifications and stopping offending. And yet they had little hope of achieving what many described as 'normality' in life (namely the status that comes with such achievements), partly because of misrecognition from the wider society which left many resigned to the fact that their goals were unlikely to be achieved in the foreseeable future. This was particularly the case for the young men in the sample whose goals had eluded most of them in the 10 years between interviews. Vic was an exception, in that he was anticipating the status and responsibilities of fatherhood (as his girlfriend was pregnant at the time of his second interview in 2010), and he seemed determined to overcome any obstacles resulting from potential misrecognition from the criminal justice system or Children and Families Social Work Department in the interim. Despite the social work department monitoring the situation (both he and his partner were currently on Drug Treatment and Testing Orders), he was determined to stay clean for his child:

I know fine when the kid comes... there'll be social workers and that involved because of the drugs, and if I'm not as crystal clear as can be, it's not gonna look very good for the bairn, and I wouldn't want the bairn taken away from me... [Before] I had no ties, no kids, no nothing... now at this stage right now there's too much to lose, you know. I've got the girlfriend... It'd be my own kid, it'd be my own house, you know, everything I've worked up for (Vic). 
Vic's relationships with his drugs counsellor and social worker were based on mutual respect. His social worker wanted him to speak to school pupils about offending and drug misuse, and he was keen to do this on a voluntary basis: 'I could tell 100 bairns and if it sinks into one bairn's head, it could be a bonus... that's what I'm planning on doing'. Thus, Vic had a purpose in life, to raise a family of his own, and to offer his experiences of offending as a means of deterring other young people; such generativity is a strong source of reciprocal recognition.

When asked at the age of 21 what she had achieved in her life to date, Anna could only think of one achievement which was winning an award as a trainee beautician, although this did not help her find work. Opportunities for mainstream integration only came five years later when she came off heroin at the age of 26; was prescribed methadone; got accepted on a college course in counselling; and became a member of a service user self-help group, through which she spoke to professionals and users about the harmful effects of drug misuse. Like Vic, this stability and generativity gave Anna recognition - a purpose in life and the acknowledgement of such by someone whom she respected, namely her drugs counsellor:

I felt as if I had a voice and I felt - I didn't feel a scumbag...I got a really, really good drug counsellor, really good. He was brilliant. He believed in me, which I hadn't had all my life. I mean my parents, no one had, you know. I'd never felt a positive relationship with anyone (Anna).

Emma, on the other hand, had no obvious sources of recognition in her life to date. At the age of 26 , she was adamant she wanted to come off drugs, come off methadone, get her children 
back and go to college, but her family had rejected her and she felt that many professionals had too. She desperately needed more proactive support but at the time of interview it had not been forthcoming, despite her being in prison:

When I was in [homeless hostel], I had like a key worker and she was there all the time. I feel like I need, cos I'm always on my own, so I end up going with - like seeing [associates] and going with them and then whatever they're doing, I end up doing, do you know what I mean? So if I had like somebody to say - I know nobody could hold my hand and say 'oh you've got to do this and you've got to do that', but I would like somebody to hold my hand. Do you know what I mean? To kind of like support me. That's what I need, is support.... But there is no support... if I had something to work towards, you know, like if they say something like, right if you do this for so many months, then you can start having the bairn... then I would keep on doing it (Emma).

\section{ON THE CUSP OF RECOGNITION}

Disadvantaged young people generally have limited power through which to invest in the responsibilities and achievements which result in mainstream integration and recognition. They are more marginalised than their law-abiding and affluent peers, they can be subject to misrecognition by criminal justice and wider social policies, and they may seek to gain identity and recognition from within their immediate peer group for as long as sustainable. The reason why such young people can be said to stand 'on the cusp of recognition' (Markell, 2007: 103) is because of their liminal status and limited access to opportunities in youth through which to take on responsibilities for themselves or others and thereby achieve actual 
or potential recognition. Hence the importance of the concept of redistribution since legitimate investment and reward are only available to those young people with the resources and opportunities to make an actual or potential contribution within [adult] society. In his seminal work on Japan's reaction to fluctuating crime rates in recent decades, Leonardsen (2003) refers to offenders as 'people loosely integrated into the established society' (ibid: 206):

The main reason why most crime is committed by youth is because it is the period when these people to a large degree are outside primary groups like job fellowships and families. They are, in brief, in a situation of no responsibility (Leonardsen, 2003: 221).

This situation of 'no responsibility' is what creates disrespect and misrecognition. Poverty both in terms of resources and opportunities - exacerbates the liminality of youth; the poor have to struggle for recognition in an environment where poverty is seen as an individual rather than a structural deficit. Young (2007) argues that such 'othering' of the poor is justified by the wider society on the grounds more of culture than class. He suggests that policies to reduce social exclusion are administrative rather than structural and that the solution is cosmetic, akin to what Fraser (2003) would describe as affirmative politics (in effect, rearranging the deckchairs on the Titanic) rather than transformative politics (eliminating the underlying structural causes of injustice): in other words, reactive in favour of the status quo rather than proactive in favour of redistribution. Young (1999) notes that affirmative recognition is the basis of mainstream multiculturalism, where minority groups are valorized by subsidy and assimilation, whereas transformative recognition deconstructs and destabilises existing identity differentiations and rebuilds afresh. 
However, even transformative policies and practices tend to be underplayed by recognition theorists. Garrett (2010), for example, suggests that a focus on interpersonal misrecognition 'obscures the extent to which identity and subjectivity are penetrated by structural dynamics of power' (p. 1528, quoting McNay, 2008: 9). Garrett concludes that: 'most accounts of recognition theory... tend to under-theorize the state and its role in generating and sustaining patterns of 'othering' and (mis)recognition' (ibid: 1530). Markell (2007) likewise suggests that recognition theorists primarily focus on the misrecognized rather than the misrecognizers. This would equally be the case for young offenders who are often purposefully marginalized from mainstream culture, but are vilified for their subsequent behaviour, blamed for their own predicament and contained within a punitive rather than a reintegrative social welfare and justice system.

Although not referring to young people per se, Fraser $(1995 ; 2003)$ argues for the more marginalized to be given parity of participation whereby the potentiality for justice and recognition can be transformed into actuality. She suggests that the remedy for socioeconomic injustice is political-economic transformation (for example, income/labour redistribution) and that the remedy for cultural injustice is symbolic transformation (revaluing disrespected groups, transforming everyone's sense of self, not just those disadvantaged by a dominant culture). Affirmative measures, whereby injustice is minimised without disturbing the underlying structural framework, cannot offer a sustained remedy to current struggles for recognition. For young offenders currently, affirmative remedies for injustice mean employability programmes, cognitive behaviour programmes or targeted access to benefits, all of which give some semblance of proactivity on the part of the Government but can often 
exacerbate the problems that politicians are trying to hide, namely the marginalisation and disaffection of young people.

Transformative remedies, on the other hand, might mean restructuring benefits to make them universal and accessible to all, overhauling employment legislation to ensure equal access to employment, and equalising access to justice, and responses by justice agencies, irrespective of age and status. Young (1999: 153) has argued that 'the redistribution of work as well as of income is a vital political necessity' and that full employment in particular can encourage socioeconomic equality as well as a sense of achievement and overall subjective wellbeing; to deny young people such opportunities is a direct form of misrecognition. If, as Taylor (1992: 25) suggests, '[d]ue recognition is not just a courtesy but a vital human need', then this applies not only to people irrespective of race, gender and class, but also to people irrespective of age and offence history. For many young people, being caught for offending is a major deterrent to continuing to offend, but not because of the presence - or legitimacy - of the rule of law but because of the lack of encouragement and investment in social integration following criminal justice system involvement. If crime is a means of gaining recognition from others, however misconceived, then the criminal justice system is counterproductive in that it isolates the actor and individualises the act. In so doing, the criminal justice system is both stigmatising and othering and undermines the giving and receiving of recognition in youth.

\section{CONCLUSIONS}

This article offers a new perspective on offending and desistance in the transition to adulthood by appropriating the concept of recognition from the discipline of moral 
philosophy. In assessing whether recognition is a matter of culture or economics, selfrealization through interpersonal relationships or equality through redistribution, moral philosophers have inadvertently highlighted the dichotomy in criminology of agency versus structure and individualization versus intervention, and despite not touching specifically on the issues for young people in transition, these philosophers have nevertheless raised the stakes in terms of criminology's inability to fully address the macro political, economic, moral and cultural dimensions of the governance of disadvantaged young people in transition who often bear the brunt of misrecognition, marginalisation, discrimination and victimization. Recognition theory has relevance to, and implications for, criminology and criminal justice, not least because of the suggested interface between youth offending, youth transitions and the age-crime curve. Recognition gained from peers through offending can be as crucial for young people as that gained from mainstream society through 'normality'. Yet, as Currie (2004: 255) notes, mainstream society has become carelessness about its young people, and the values of mutuality and reciprocity have been superseded by 'a shouldershrugging individualism'. To recognise the state as legitimate and to benefit from investment in opportunities in return for one's [potential] contribution to society, by definition, requires attention to the marginalization and individualisation of youth, and to the aggravating role of criminal justice and social welfare systems that prioritise and prolong individualisation and responsibilisation over integration and structural change.

Fraser (2003) concludes that transformative change through redistribution and parity of participation requires a more proactive role from politicians, policymakers and the wider community. This article further concludes that young people in transition need transformative measures for integration, and will continue to experience marginalization and inequality of opportunity unless the government takes primary responsibility for reducing the negative 
connotations of their liminality through mutual investment and reward. Only then can we ensure that disadvantaged young people no longer remain on the cusp of recognition.

\section{REFERENCES}

Anderson, J. (1995) 'Translator's Note and Introduction' in A. Honneth, The Struggle for Recognition: The Moral Grammar of Social Conflicts, Cambridge, Massachusetts: MIT Press.

Barry, M. (2013) 'Desistance by Design: Offenders' reflections on criminal justice theory, policy and practice', European Journal of Probation, Vol. 5, No. 2, pp 47-65.

Barry, M. (2006) Youth Offending in Transition: The search for social recognition, Abingdon: Routledge.

Benjamin, J. (1988) The Bonds of Love: Psychoanalysis, feminism and the problem of domination, New York: Pantheon Books.

Bottoms, A.E. and Shapland, J. (2011) 'Steps towards desistance among male young adult recidivists', in S. Farrall, M. Hough, S. Maruna and R. Sparks (eds) Escape routes: contemporary perspectives on life after punishment. London: Routledge, pp. 43-80.

Bourdieu, P. (1986) 'The Forms of Capital' in J.G. Richardson (Ed.), Handbook of Theory and Research for the Sociology of Education, Westport, CT: Greenwood Press. 
Burnett, R. (2004) 'To reoffend or not to reoffend? The ambivalence of convicted property offenders', in S. Maruna and R. Immarigeon (eds) After Crime and Punishment: Pathways to offender reintegration, Cullompton: Willan.

Canton, R. (2012) 'The point of probation: On effectiveness, human rights and the virtues of obliquity', Criminology and Criminal Justice, 13 (5): 577-593.

Currie, E. (2004) The Road to Whatever: Middle-class culture and the crisis of adolescence, New York: Holt.

Farrall, S. (2002) Rethinking What Works with Offenders, Cullompton: Willan.

Farrall, S. and Bowling, B. (1999) 'Structuration, human development and desistance from crime', British Journal of Criminology 39, 253-68.

Fraser, N. (2003) 'Social justice in the age of identity politics: Redistribution, recognition and participation', in N. Fraser and A. Honneth (eds) Redistribution or Recognition? A policitalphilosophical exchange, London/New York: Verso.

Fraser, N. (1997) Justice Interruptus: Critical Reflections on the Post-Socialist Condition, London: Routledge.

Fraser, N. (1995) 'From Redistribution to Recognition? Dilemmas of Justice in a 'PostSocialist' Age', New Left Review, 212, Jul/Aug: 68-93. 
Gadd, D. (2006) 'The role of recognition in the desistance process: A case analysis of a former far-right activist', Theoretical Criminology, 10 (2): 179-202.

Gadd, D. and Farrall, S. (2004) 'Criminal Careers, Desistance and Subjectivity: Interpreting Men's Narratives of Change', Theoretical Criminology, 8 (2): 123-156

Garland, D. (2001) The Culture of Control: Crime and Social Order in Contemporary Society, Oxford: Oxford University Press.

Garrett, P. (2010) 'Recognising the Limitations of the Political Theory of Recognition: Axel Honneth, Nancy Fraser and Social Work', British Journal of Social Work, 40, 1517-1533.

Giordano, P, Cernovich, S. and Rudolph, J. (2002) 'Gender, crime and desistance: Toward a theory of cognitive transformation', American Journal of Sociology, 107: 990-1064.

Gottfredson, M. R. and Hirschi, T. (1990) A General Theory of Crime, Stanford, CA: Stanford University Press.

Harris, H.S. and Knox. T.M. (1979) 'System of Ethical Life' and 'First Philosophy of Spirit', Albany NY: Suny Press.

Hart, E. (2014) 'Women Prisoners' Resettlement and the Struggle to Desist', paper presented at the British Society of Criminology Conference, July: Liverpool. 
Healy, D. (2013) 'Changing fate? Agency and the desistance process', Theoretical Criminology, 17(4): 557-574.

Healy, D. (2010) The Dynamics of Desistance: Charting pathways through change, Cullompton: Willan.

Honneth, A. (2007) Disrespect: The normative foundations of critical theory, Cambridge: Polity Press.

Honneth, A. (1995) The Struggle for Recognition: The moral grammar of social conflicts, translated by J. Anderson, Cambridge, MA: MIT Press.

Laitinen, A. (2003) 'Social equality, recognition and preconditions of good life', Social Inequality Today, Macquarie University, 12 November, CRSI Conference Proceedings.

LeBel, T., Burnett, R., Maruna, S. and Bushway, S. (2008) 'The "Chicken and Egg” of Subjective and Social Factors in Desistance from Crime', European Journal of Criminology, Vol. 5 (2): 131-159.

Leonardsen, D. (2003) 'Crime in Japan - a lesson for criminological theory?' Selected papers from the 2003 British Criminology Conference, Bangor, June, British Society of Criminology, Vol. 6.

Liem, M. and Richardson, N. (2014) 'The Role of Transformation Narratives in Desistance among Released Lifers', Criminal Justice and Behavior, Vol. 41, No. 6: 692-712. 
Markell, P. (2007) 'The Potential and the Actual: Mead, Honneth and the "I"', in B. Van den Brink and D. Owen (eds) Recognition and Power: Axel Honneth and the Tradition of Social Theory, New York; CUP: 100-134.

Maruna S (2001) Making Good: How Ex-Convicts Reform and Rebuild their Lives American Psychological Association Books, Washington DC.

Maruna, S. and Matravers, A. (2007) 'N=1: Criminology and the person’, Theoretical Criminology, Vol. 11 (4): 427-442.

McAra, L. and McVie, S. (2010) 'Youth crime and justice: Key messages from the Edinburgh Study of Youth Transitions and Crime', Criminology \& Criminal Justice, 10 (2): 179-209.

Merton, R. (1957) Social Theory and Social Structure, New York: Free Press.

Moloney, M., MacKenzie, K., Hunt, G. and Joe-Laidler, K. (2009) 'The path and promise of fatherhood for gang members', British Journal of Criminology, 49: 305-325.

Morizot, J. and Le Blanc, M. (2007) 'Behavioral, self and social control predictors of desistance from crime: A test of launch and contemporaneous effect models', Journal of Contemporary Criminal Justice, 23 (1): 50-71. 
Nugent, B. and Barnes, P. (2013) ‘Desistance and Young People: Includem’s work with children and young people and the limitations of desistance theory', Scottish Justice Matters, December: 21-23.

Princes Trust/Macquarie (2014) Youth Index 2014, London: Princes Trust.

Rauch, L. (1983) Hegel and the Human Spirit: A Translation of the Jena Lectures on the Philosophy of Spirit', Albany, NY: Suny Press.

Rose, N. (2000) 'Government and Control', British Journal of Criminology, 36 (4): 321-339.

Rutherford A (1986) Growing Out of Crime: The New Era Winchester: Waterside Press.

Sampson, R.J. and Laub, J. (2005) 'A Life-Course View of the Development of Crime', Annals of the American Academy of Political and Social Science, 602: 12-45.

Sampson, R.J. and Laub, J. (1993) Crime in the Making: Pathways and turning points through life, Cambridge, MA: Harvard University Press.

Shapland, J. and Bottoms, A. (2011) 'Reflections on social values, offending and desistance among young adult recidivists', Punishment \& Society, 13(3) 256-282.

Shover, N. (1996) Great Pretenders: Pursuits and Careers of Persistent Thieves, Boulder, CO: Westview Press. 
Taylor, C. (1992) Multiculturalism and the Politics of Recognition, Princeton, NJ: Princeton University Press.

Vaughan, B (2007) The Internal Narrative of Desistance, The British Journal of Criminology 47 (3): 390-404.

Wacquant, L. (2012) 'The wedding of workfare and prisonfare in the $21^{\text {st }}$ century: Responses to critics and commentators', in P. Squires and J. Lea (eds) Criminalisation and advanced marginality: Critically exploring the work of Loic Wacquant, Bristol: Policy Press, pp. 243257

Weaver, B. (2015) Offending and Desistance: The significance of social relations, Abingdon: Routledge.

Young, J. (2007) The Vertigo of Late Modernity, London: Sage.

Young, J. (1999) The Exclusive Society, London: Sage. 